\title{
EL TRABAJO POR CUENTA PROPIA. INCIDENCIAS EN EL NUEVO RELANZAMIENTO EN LA APLICACIÓN DEL MODELO ECONÓMICO DE CUBA EN EL SIGLO XXI
}

\author{
Alcides Francisco Antúnez Sánchez \\ Jorge Manuel Martínez Cumbrera \\ Jorge Luis Ocaña Báez \\ Universidad de Granma, Cuba
}

http://dx.doi.org/10.5209/rev_NOMA.2013.42344

\begin{abstract}
Resumen.- El tema tratado erige como problemática el análisis del trabajo por cuenta propia desde la óptica del Derecho Mercantil en Cuba, con énfasis en su régimen jurídico y concreción del Derecho Mercantil cubano y en el perfeccionamiento del nuevo modelo económico cubano en este siglo XXI, destacando la inserción de la figura femenina en esta actividad. Como objetivo nos proponemos determinar la situación actual del trabajo por cuenta propia en el Derecho Mercantil cubano, así como su regulación jurídica. Partiendo del concepto de trabajo por cuenta propia, se fija el cuestionamiento sobre si aceptar o no al cuentapropista como un empresario mercantil individual o no y, la evolución que este ha tenido desde comienzos del triunfo revolucionario hasta la actualidad en sus etapas, por un lado, y por otro, se determinan los requisitos para ejercer las actividades autorizadas, las causas para que su labor quede extinguida y un análisis de las diferentes regulaciones jurídicas encargadas de regular el mismo. Se emplearon como métodos el exegético jurídico y el histórico lógico. Del análisis de los principios en que se informa la legislación que rige en Cuba para los trabajadores por cuenta propia se aprecia una ruptura conceptual elemental en cuanto a la actividad que pueden desarrollar estos y la que realizan los empresarios individuales, toda vez que la primera se desarrolla solo como complemento de la actividad estatal, siendo renovable la autorización para su ejercicio, con carácter municipal y solo les está permitido actuar de forma personal, mientras que el empresario individual actúa por su propia cuenta y también por cuenta de terceros, pudiendo actuar por medio de representantes, con el límite que pueda establecer la ley para actividades mercantiles, sin limitaciones territoriales. Significando el divorcio entre la legislación mercantil y las que han sido emitidas por la Administración Pública en relación con esta actividad mercantil, cuyo organismo que ejerce el control y la autorización es el Ministerio de Trabajo y Seguridad Social, no registrándose los mismos en el Registro Mercantil, con las obligaciones de contribuir con la legislación tributaria.
\end{abstract}

Palabras clave.- derecho mercantil, trabajo por cuenta propia

Abstract.- The treated theme, erect like problems the analysis of work at your own risk from the optics of The Mercantile right in Cuba, with emphasis in his juridical regimen and concretion of The Mercantile right Cuban and in the perfecting of the new cost-reducing model Cuban in this century $X X I$, highlighting the insertion of the feminine figure in this activity. We propose determining the present-day situation of work at our own risk in The Mercantile right like objective Cuban, as well as his juridical regulation. Departing from the item of work at one's own risk, you fix the interrogation be more than enough if accepting or no to the cuentapropista like a mercantile individual businessman or no and, the evolution that this has had from beginnings of the revolutionary triumph to the present time in his stages, on the one hand, and for another one, they determine the requirements to exercise the authorized activities, causes in order that his work get extinguished and an analysis of the different juridical regulations entrusted of regular customer the same. They used like methods the exegetic juridical and the historic logician. You appreciate a conceptual elementary rupture as to the activity that these and the one that the individual businessmen accomplish can develop of the analysis of the beginnings the legislation that is in effect in Cuba for the independent labor force informs itself in, inasmuch as the first develops only like complement of the state-owned activity, being renewable the authorization for its exercise, with municipal character and only he is for to 
them allowed acting of personal form, while the individual businessman acts on his own account and also for account of third parties, could have acted by means of representatives, with the limit that you may establish herLaw for mercantile activities, without territorial limitations. Signifying the divorce between the mercantile legislation and the ones that have been emitted by the Public Administration relating to this mercantile activity, whose organism that exercises the control and the authorization is the Department Of Labor and Social Security, no getting registered the same in the Mercantile Register, with the obligations to contribute with tax legislation.

\section{INTRODUCCIÓN}

A inicios de la década de 1990 del pasado siglo nuestro país comenzó a enfrentar la más profunda crisis económica de su historia, influenciada principalmente por el derrumbe del campo socialista y el recrudecimiento del bloqueo económico por parte de Estados Unidos, por lo que era urgente salir de la misma, sin renunciar a nuestro proyecto social socialista, al modelo de económico y a todas las conquistas alcanzadas. Ante esta situación se tomaron una serie de medidas con el objetivo de reestructurar la economía y hacerle frente a dicha crisis; destacándose la legalización de la tenencia de divisas convertibles instaurándose en el país la doble circulación monetaria, la apertura a la inversión de capital extranjero y el lanzamiento del trabajo por cuenta propia, en septiembre de 1993, a través del Decreto-Ley 141 Sobre el ejercicio del trabajo por cuenta propia, el cual revitalizó esta institución, autorizándose nuevas actividades que podían ser ejercidas por estos trabajadores inscritos formalmente, dictándose posteriormente otras normas complementarias que se encargarían de regular dicha actividad. El fortalecimiento del trabajo por cuenta propia empezaría a cumplir, en nuestro país, con objetivos muy definidos, tales como la constitución de una alternativa más de empleo; ya que surge, además como respuesta al creciente desempleo que caracterizaba la década de los años noventa; formaría además un complemento de la actividad estatal en la producción de bienes y la prestación de servicios útiles a la población; porque el Estado hasta ese momento se encontraba sobrecargado de funciones económicas, es decir, tenía en su poder todas las esferas de la producción y los servicios, posición que no podía seguir asumiendo por su condición de ente improductivo y por otros factores decisivos como el de ser un país bloqueado y subdesarrollado, de esa forma se hacia urgente poner en práctica esta actividad; también para los que lo ejercieran representara una vía de incremento de los ingresos personales y por último, sería un aporte más al presupuesto estatal a través del cobro de los tributos, que en esta propia década se establecieron al crearse la Oficina Tributaria. El Trabajo por cuenta propia, en la actualidad, es un tema trascendental ante el nuevo proceso de reestructuración de la economía cubana que se lleva a cabo a partir de la implementación de los Lineamientos de la Política Económica y Social del Partido y la Revolución en el año 2012, con el relanzamiento se entra a fortalecer la actividad, aprobándose 
nuevas formas de ejercer la misma y otros privilegios para quienes la practican, los cuales serán tratados más adelante.

\section{1.- El trabajo por cuenta propia en Cuba desde la óptica del derecho mercantil cubano}

Antes de analizar cualquier tema en cuestión debemos partir de su definición, de que es, realmente el término del cual estamos hablando; por eso abordaremos primeramente, ¿Qué entender por Trabajo por cuenta propia?

En la doctrina jurídica encontramos varias definiciones del Trabajo por cuenta propia, por ejemplo un colectivo de autores del CEDEM lo define como todas aquellas actividades desarrolladas por agentes económicos, fuera de los dos sectores sociales fundamentales de la economía socialista, es decir, el sector estatal y el cooperativo. ${ }^{1}$

Otros autores, como Rayza Fraga y Nathasha Mesa, lo definen como la persona natural cubana con edad laboral, que autorizada por las direcciones municipales de trabajo, previa autorización de las organizaciones políticas y de masas, realiza una actividad económica a cambio de la obligación de pagar el impuesto correspondiente. $^{2}$

Hay quienes lo llegan a confundir con el trabajo informal, es decir, como la actividad económica con fines lucrativos, que queda fuera de toda regulación estatal, o sea, al margen de la ley; del que no se ignora su presencia, en la sociedad cubana, pues dentro de esta consideración puede hallarse a trabajadores por cuenta propia $u$ otros, que no hayan acatado las regulaciones que al efecto ha dictado el Estado cubano, y se encuentren, por lo tanto, al margen de las disposiciones jurídicas, pero a mi criterio no se puede confundir al trabajo por cuenta propia en el ámbito del trabajo informal, pues el individuo autorizado al ejercicio de las labores establecidas como tal no pueden actuar fuera del marco legal vigente en el territorio nacional, es decir, los productos que ellos comercializan o los objetos de sus prestaciones deben ser de una procedencia licitad.

Además no se puede considerar a todos los que se dedican a actividades de carácter económico, sin una previa autorización por el organismo competente como trabajadores por cuenta propia; entendiendo por estos como aquella persona natural, que habitualmente una actividad de comercio, o de prestación de

\footnotetext{
1 Temas de Derecho Mercantil. Libro de texto de pregrado, para el estudio de la carrera de Derecho. Ministerio de Educación Superior. República de Cuba. Editorial Félix Varela. 2005.

2 Ibídem No.1.
} 
servicios, en nombre propio, con un ánimo de lucro y cumpliendo todas las formalidades legales establecidas para ello. ${ }^{3}$

Cuando hablamos de dar una definición de trabajo por cuenta propia, en nuestra doctrina jurídica y en el ordenamiento jurídico cubano, debemos hacer énfasis a la disyuntiva existente entre si ver o no, al cuentapropista como un empresario mercantil individual o no, definiendo a este último cómo la persona natural o física, que desarrolla habitualmente en el mercado una actividad económica de comercio, industria o servicios, en nombre propio y con ánimo de lucro. Aquellos que ven estas figuras separadas plantean, que a pesar de ser el cuentapropista una persona natural, que en nombre propio realiza una actividad económica en el mercado de manera habitual y profesional, cumpliendo con las obligaciones recogidas en el Estatuto del empresario, realiza actividades que quedan en el marco de actividades civiles como la agricultura, artesanado y profesiones liberales. ${ }^{4}$

Otros, sí ven al trabajador por cuenta propia como un empresario mercantil individual, con la cual nos afiliamos, porque este en muchos casos si practican actividades, que van más allá del ámbito civil, por ejemplo, los que para ejercer su labor han contratado un número de personas que tienen como funciones asegurar el cumplimiento de la prestación de un servicio, "en las denominadas Paladares y cualquier otra actividad gastronómica que les sea permitido contratar otras persona". 5

La disyuntiva sobre el Trabajo por cuenta propia en nuestro país se ha hecho extensiva hasta en la forma de regular jurídicamente la institución ya que, el régimen establecido para su autorización, sus obligaciones, sus derechos es función de las Direcciones de Trabajo Municipales, instituciones pertenecientes al Ministerio de Trabajo y Seguridad Social.

Igual sucede con el registro de estos trabajadores, el cual según la Resolución No. 33 de 6 de septiembre de 2011, del Ministerio de Trabajo y Seguridad Social debe realizarse en las Direcciones de Trabajo $^{6}$, además, de la que están obligados a realizar en la Oficina Nacional de Administración Tributaria( en lo adelante ONAT $)^{7}$, inscribiéndose como contribuyentes; lo cual difiere de lo regulado para los empresarios mercantiles individuales, en el Código de Comercio, en su artículo

\footnotetext{
3 Código de Comercio de la República de Cuba. 1886. (Legislación de Ultramar) España. (vigente aún en el territorio nacional).

4 Ibídem No.1, pág.17.

${ }^{5}$ Legislación en materia de trabajo no estatal emitidas por el Ministerio de Trabajo y Seguridad Social, en relación con el ejercicio del Trabajo por Cuenta propia en Cuba, y las actividades autorizadas a realizar por parte de las personas naturales.

${ }^{6}$ Se refiere a la oficina tributaria, perteneciente al Ministerio de Finanzas y Precios. Organismo de la Administración Pública, encargada del cumplimiento de la política fiscal.

${ }^{7}$ Oficina Fiscal en Cuba, perteneciente al Organismo de la Administración Pública ( Ministerio de Finanzas y Precios), quien se ocupa de toda la política fiscal del país en relación con las personas naturales y jurídicas.
} 
16 apartado primero, cuando establece la obligación de inscribir en el Registro Mercantil a los comerciantes particulares ${ }^{8}$, emitiéndoles el correspondiente aval como comerciante.

Por lo tanto debemos afirmar que en nuestro país el trabajador por cuenta propia es un empresario mercantil individual, pero que por una decisión del Estado (Administración Pública), se regula su actividad de forma diferente a la establecida en el ámbito mercantil internacional. También se puede mencionar que al trabajador por cuenta propia se le pudiera ver en dos aristas; una desde la mercantil fundamentándose con los criterios antes expuestos $\mathrm{y}$, otra, desde la óptica laboral, viéndolo como una persona que realizando algunas de las tareas reguladas para ello lo haga sola, de forma que no necesite la intervención de un tercero para su desarrollo no tiene una relación jurídica de carácter laboral porque no se encuentra subordinado jerárquicamente a ninguna otra persona, el resultado de su trabajo le es propio, no posee salario, está sujeto a la ley de la oferta y la demanda y sus ingresos varían en dependencia de esta. Pues al revisar nuestro Código de Trabajo, la Ley No. 49, de 28 de diciembre de 1984, establece en su artículo 5: [...] las relaciones jurídico-laborales que se regulan en el presente Código son aquellas que surgen de la vinculación laboral del trabajador con las entidades laborales mediante el contrato de trabajo o la designación para desempeñar una ocupación o cargo, o como resultado de la elección para ejercer determinadas funciones, recibiendo por ello la remuneración establecida en cada caso. Por lo tanto la relación jurídica laboral en los cuentapropistas tiene lugar en el caso de aquellos casos donde una persona autorizada para el ejercicio del trabajo por cuenta propia contrate fuerza laboral, en este caso si existe una relación de subordinación y se percibe una remuneración, predominando el contrato verbal, no estando aún regulado en nuestra normativa en materia laboral. $^{9}$

Es criterio de los autores que hay que tener presente cuando se aborde el cuestionamiento si hay relación jurídico-laboral con los cuentapropistas, si aquellos autorizados previamente que contratan su fuerza de trabajo se pueden considerar como empresarios mercantiles. Lo anterior excluye la posibilidad de tutelar, desde las normas del Derecho Laboral, la actividad por cuenta propia o trabajo no estatal como también se le denomina; razón por la cual el Estado cubano ha regulado y controlado estas actividades mediante normas de carácter

\footnotetext{
${ }^{8}$ Registro Mercantil, ubicado en las Direcciones Provincial de Justicia, pertenecientes al organismo de la Administración Pública (Ministerio de Justicia), quien entre sus funciones tiene la de registrar todos los actos mercantiles que se susciten en el territorio de su demarcación. Refiriéndonos que por decisión estatal los pequeños comerciantes no se inscriben en este registro, lo ejecutan en las Direcciones Municipales de Trabajo, pertenecientes al Ministerio de Trabajo y Seguridad Social. En contradicción como se dispone en el Código de Comercio vigente en la República de Cuba.

${ }^{9}$ Revisar la Ley No. 49 de 1984, actual Código de Trabajo de Cuba, y las modificaciones posteriores en materia laboral y en especial en materia de contratos laborales que se han ido realizando al mismo, tal como las establecidas en materia de política de empleo en la Resolución No. 8 del año 2005 emitida por el Ministerio de Trabajo y Seguridad Social.
} 
administrativo y tributario, no introduciendo en las relaciones civiles entre estas personas naturales, ya que debió colegirse desde sus inicios de esta manera.

\section{La evolución del Trabajo por Cuenta Propia en el proyecto social cubano}

La actividad privada en Cuba durante la etapa revolucionaria ha tenido varios momentos, a partir de 1959 a pesar de las reformas económicas y sociales, fue aplicado un proceso de nacionalización, llevadas a cabo para la construcción del nuevo proyecto social socialista; en el país siguieron existiendo trabajadores privados, concentrados fundamentalmente en campesinos individuales, transportistas y algunas profesiones como médicos, estomatólogos, optometristas, veterinarios, tomando como punto de partida el Decreto-ley No. 14 de 1978, referido al trabajo por cuenta propia como actividad permitida, con la distinción que el personal profesional tenia que ser graduado antes del año $1959 .{ }^{10}$

En Cuba, en el período anteriormente señalado, se encontró como solución para los casos de profesionales y técnicos titulados, graduados con anterioridad al año 1964, que ejercían y continuaron el ejercicio privado de la profesión de manera ininterrumpida y cumpliendo con las formalidades exigidas, la inclusión en las normas jurídicas que autorizan la actividad por cuenta propia (y en cada nueva legislación sobre la materia se le da continuidad a la autorización para ejercer), sin posibilidad de nuevas incorporaciones, dado el carácter estatal y social como conquista del proyecto revolucionario que tiene la asistencia médica, estomatológica y veterinaria en el país, a diferencia de la mayoría de las legislaciones, en las cuales se distingue a los profesionales titulados de los empresarios mercantiles, pero tampoco se les atribuye la condición de trabajador por cuenta propia.

También se evidencia que antes del año 1990 los trabajadores por Cuenta Propia tenían entre sus características principales: los estrechos límites que imponía la legislación a las características sociodemográficas y profesionales del grupo; concentración en la esfera de la circulación o recirculación de bienes y servicios con escasa presencia en la esfera de la producción; elevado promedio de edad de sus miembros; nivel de instrucción y calificación bajo; con tendencia al crecimiento no legal de este grupo y un fuerte vínculo con la economía sumergida, recordar que nos encontrábamos en el denominado período especial, decretado de esta forma por parte del Estado.

Luego con la implementación del Decreto-Ley No. 141 en 1993, se amplía la actividad por Cuenta Propia en Cuba y estaría dentro de lo que es el sector privado, aunque solo constituye una parte de éste, dado que en la sociedad cubana opera también el capital mixto, resultado de asociaciones entre el capital extranjero y estatal nacional; el campesinado individual, entre otras figuras

10 Consultar la Gaceta Oficial de la República de Cuba, disponible en la página web www.gacetaoficial.cu, del Ministerio de Justicia en la República de Cuba. La Habana. 
privadas que no son cuentapropistas, con las modificaciones constitucionales realizadas en este sentido y la emisión de una norma jurídica con rango de ley que implementó la inversión extranjera, con facilidades a empresarios extranjeros. ${ }^{11}$

Con la promulgación del Decreto- Ley No. 141 en 1993 se podían ejercer 55 actividades, posteriormente en el año 1995 se autorizan 117 y en el 2002, estaban registradas 157. Como se aprecia, se permitió un mayor espacio a la actividad privada o no estatal y se estima que estas actividades no sólo constituyeron una fuente emergente de empleo, sino que complementaron la actividad estatal y oferta de bienes y servicios que no existían en otros mercados, adicionalmente constituyó una nueva vía de ingresos para la familia cubana en este momento histórico.

Con la apertura y extensión de las actividades por Cuenta Propia, en los años de la década del 90, esta decisión del Estado permitió que se comenzara a percibir una disminución de la economía sumergida, y se produjera una evolución de lo ilegal a lo legal, principalmente, a través, de la ampliación del número de actividades autorizadas en el sector no estatal.

El referido Decreto - Ley no definió el trabajo por cuenta propia; encargó al Ministerio de Trabajo y Seguridad Social la determinación de las actividades que podrían realizarse por concepto de ese desempeño, los sujetos de dicha labor, los requisitos para ejercerlas, la forma de comercialización de los productos 0 servicios y el ordenamiento, control y supervisión de sus actividades, estableciendo la obligatoriedad de inscripción en el Registro de Contribuyentes ${ }^{12}$, previo el pago de los derechos correspondientes a dicha inscripción (que es independiente del que se realiza en virtud de los impuestos que gravan este tipo de labor); así como al Ministerio de Finanzas y Precios para la regulación del procedimiento a los efectos de la liquidación y pago del impuesto correspondiente, y otras reglamentaciones referidas a dicha norma. ${ }^{13}$

De esta manera, los trabajadores por cuenta propia quedaron obligados no sólo a declarar su actividad, sino a ostentar la autorización pertinente, estando su desempeño sujeto a diversas inspecciones estatales para verificar el cumplimiento de normas sanitarias ${ }^{14}$, tributarias, administrativas, etc. Posteriormente, y para ordenar la aplicación del Decreto-ley se dictaron una serie de disposiciones de diferente nivel jerárquico a través de Decretos, Resoluciones e Instrucciones de los organismos competentes, todas encaminadas a regular toda la gama de actividades que por cuenta propia pueden desarrollarse bajo autorización estatal, y que dependen de la necesidad real de cada territorio. Dentro de estas disposiciones se encuentran las Resoluciones Conjuntas No. 1 de 18 de abril de

11 Consultar la Gaceta Oficial de la República de Cuba, disponible en la página web www.gacetaoficial.cu, sitio del Ministerio de Justicia. La Habana. Cuba.

${ }^{12}$ Consultar la política tributaria del país, establecida en la Ley No. 73

13 . Ibídem no. 13

${ }^{14}$ Se refiere al cumplimiento de todo lo establecido por el Ministerio de Salud, en relación con la Ley No. 41, Ley de la Salud Pública y la legislación en materia de derecho sanitario complementaria, como Autoridad Sanitaria en el país. 
1996 "Reglamento del ejercicio del trabajo por cuenta propia", la No. 1 de 10 de abril de 1998 y la No 1 de 8 de agosto de 2003, dictadas por los Ministerios de Trabajo y Seguridad Social y el de Finanzas y Precios, que respondieron a situaciones coyunturales que se produjeron en el período, en adecuación a la realidad económica del país en este momento. ${ }^{15}$

Al experimentar la economía cubana cierta reanimación a partir del año 2002, y dada la envergadura alcanzada por la actividad de trabajo por cuenta propia, se determinó introducir otras modificaciones en la legislación, atendiendo a lo que a cada organismo competía, a partir de lo dispuesto en el Decreto-ley No. 141 de 1993, dictándose la Resolución No. 11 del 2004 "Reglamento sobre el ejercicio del trabajo por cuenta propia". Este Reglamento tuvo como fundamento el reconocimiento de que el trabajo por cuenta propia actuaba a manera de complemento de algunas actividades estatales en la producción de bienes, la prestación de servicios útiles a la población y que se convirtió en una alternativa de empleo en aquellos lugares con limitaciones para el acceso a la ocupación; basándose, además, en la experiencia acumulada en la aplicación de las disposiciones sobre esta materia, y la posibilidad de que un grupo de actividades fueran asimiladas por diferentes órganos y organismos de la Administración Central del Estado. ${ }^{16}$

En el Reglamento tampoco se conceptualiza el trabajo por cuenta propia; en su articulado solo se regularon las actividades que, bajo esa denominación, podían realizarse, así como el procedimiento para ello, su ordenamiento, supervisión y control. Sí se relacionan los principios generales que rigen su ejercicio, a saber: actúa como complemento de la actividad estatal; se ejerce de forma individual; la autorización para su ejercicio es renovable; abarca las actividades de producción y comercialización de los bienes y servicios en el domicilio del titular; solo se podrá ofertar las producciones y servicios a personas naturales; tiene un carácter municipal.

Reglamento que fue derogado expresamente por la Resolución No 9 del 2005, que tuvo como fundamento la experiencia acumulada en la implementación de la Resolución No. 11 del 2004, así como la imposibilidad de que un grupo de actividades que se venían realizando, mediante el ejercicio del trabajo por cuenta propia, fueran asimiladas por diferentes órganos y organismos de la Administración Central del Estado. ${ }^{17}$

\footnotetext{
15 Consultar la Gaceta Oficial de la República de Cuba, disponible en el sitio web www.gacetaoficial.cu, del Ministerio de Justicia. Cuba.

16 Ibídem no. 15.

17 Consultar la Gaceta Oficial de la República de Cuba, disponible en el sitio web www.gacetaoficial.cu, del Ministerio de Justicia. Cuba.
} 


\section{El relanzamiento del Trabajo por Cuenta Propia en el proyecto social cubano en la primera década del siglo XXI}

A partir del alrededor del año 2009 resultó necesario llevar a cabo un perfeccionamiento del nuevo modelo económico cubano, reordenar la economía como anteriormente se había hecho en los años de la década de 1990 del pasado siglo, motivada por factores tanto internos como externos. Dentro de los externos podemos encontrar la caracterización del entorno internacional por la existencia de una crisis estructural sistémica, con la simultaneidad de las crisis económica, financiera, energética, alimentaria, y ambiental, con un mayor impacto en los países subdesarrollados; y por lo tanto, Cuba, con una economía dependiente de las relaciones económicas externas de los impactos de dicha crisis, manifestado en la inestabilidad de los precios de los productos que intercambia, en la demanda de sus mercancías, etcétera.

El país experimentó nuevamente el recrudecimiento del bloqueo económico, comercial y financiero impuesto por los Estados Unidos de América por ya más de medio siglo. Que en el orden interno se refleja una baja eficiencia, descapitalización de la base productiva y la infraestructura, envejecimiento y estancamiento en el crecimiento poblacional. Ante estos factores se tomaron una serie de medidas encaminadas al reordenamiento del Modelo Económico cubano actual, se dictaron una serie de medidas, a través de los Lineamientos de la Política Económica y Social del Partido y la Revolución en el 6to congreso del Partido, dentro de las cuales la más importantes, fue la nueva ampliación del trabajo por cuenta propia; que para lograr su finalidad se dictaron una serie de regulaciones y disposiciones jurídicas, tales como la Resolución 32 del Ministerio de Trabajo y Seguridad Social, sustituyendo a la Resolución 33 del propio organismo, "Reglamento del ejercicio del trabajo por cuenta propia", que amplía y flexibiliza aún más el ejercicio del trabajo por cuenta propia. ${ }^{18}$

El avance organizado y dinámico, contribuye a que el Estado descentralice la prestación de un grupo de servicios y de la comercialización de bienes, y se concentre en las grandes producciones primarias que permiten el desarrollo y la generación de los ingresos que son importantes para el país. Como parte de la teoría del socialismo consiste también en dinamizar, revolucionar, siempre dentro de los principios equitativos y distributivos de este sistema social". ${ }^{19}$

Para obtener mejores beneficios del trabajo por cuenta propia se ha de conjugar el permiso a actividades intensivas en conocimiento y fomentar los vínculos entre el sector no estatal y estatal, que constituyen las dos cosas fundamentales que permitirán absorber la fuerza de trabajo excedente y convertir al sector estatal en un elemento de desarrollo para la economía cubana. Por lo tanto no debemos subestimarlo ni estigmatizarlo. Hay que entender su aporte real, no solo como

\footnotetext{
${ }^{18}$ Disponible en el sitio web www.gacetaoficial.cu, del Ministerio de Justicia. Cuba.

${ }^{19}$ Consultar Lineamientos del 6to Congreso del Partido en Cuba. 2011. Publicado por la editora del Comité Central del Partido. La Habana. Cuba.
} 
opción de empleo, sino como un elemento que va a dinamizar la economía doméstica y el intercambio de bienes y servicios entre las personas naturales. La técnica de la autorización ha sido dada a aquellas actividades que tengan una fuente de suministros clara, legal, posible. Se ha dicho que surgirán cooperativas en los sectores de la gastronomía, la industria ligera, el transporte; pero no puede empezarse decretando esas nuevas formas, las que tendrán que ir gestándose, madurando, en la medida de que la Administración Pública las vaya autorizando. ${ }^{20}$ Hoy la cantidad de trabajadores por cuenta propia está doblando la cifra existente en octubre del año 2010, mientras que la demanda del mercado sigue siendo la misma. Por tanto, se redistribuye entre más cuentapropistas autorizados a ejercer esta actividad. Se estudia si el actual sistema tributario vigente esta en correlación con los niveles de ingresos de estas personas en relación con la demarcación geográfica y otros factores externos e internos que de una manera u otra determinaran conductas y decisiones a tomar por parte del Estado, ya que de 150 mil trabajadores en un primer momento, hoy la cifra va en alrededor de mas de 330 mil ciudadanos acogidos a esta nueva forma de empleo, cuestión esta a estudiarse y tomar decisiones en este sentido. ${ }^{21}$

\section{¿Cómo se comporta actualmente el otorgamiento de licencias y la posibilidad de acceder a materias primas y otros recursos que demanda el cuentapropismo?}

Cuando se aprobó la ampliación y flexibilización del trabajo por cuenta propia, en septiembre-octubre del año 2010, ejercían esta modalidad unas 157 mil personas. En agosto del año 2011 ya eran 333 mil 206. Entre las actividades más representativas se ubican las de transporte, la elaboración de alimentos, el arrendamiento de viviendas y trabajadores contratados. Con tendencias a que siga incrementándose.

Para el año 2011 se habían aprobado 120 millones de dólares destinados a suministros e insumos que benefician al trabajo por cuenta propia, cuestión esta a criterio de los autores no del todo cumplida por la Administración Pública, incidiendo en los precios que comercializan estos trabajadores al tener que contribuir con el fisco, y no poder adquirir materias primas al mayor como se divulgó, por lo cual considero que aún en el país no exista competencia en este tipo de empleo, y que aún el Estado no este en condiciones de darle solución a este problema cuya arista mercantil incide en la economía del ciudadano cubano cuya fuente de ingreso sea su relación jurídica laboral con el Estado, recibiendo la carga tributaria alta, al no haber una correlación entre lo que comercializa este trabajador no estatal en materia de precios.

Al duplicarse la cantidad de licencias, más allá de lo esperado, se decidió por la Administración Publica tomar alternativas, poniendo mercancía en la red minorista

\footnotetext{
${ }^{20}$ García Enterría. Derecho Administrativo. Editora Espasa. España.

${ }^{21}$ Datos expuestos en la página web del Ministerio de Trabajo y Seguridad Social. www.mtss.cu. La Habana. Cuba.
} 
en grandes volúmenes, pero sin tener en cuenta el valor. Es conocida la situación financiera que tiene el país, y aunque no hay un mercado mayorista, algunas acciones tratan de paliar tal carencia, en esto trabajan los organismos y sociedades mercantiles suministradoras, como son: TRD, Ministerio de Comercio Interior, entre otros, a través del mercado minorista; ya que aún no hay creados los mecanismos de ventas de forma mayorista en otros escenarios (almacenes venta al mayor).

Se producen bajas y es normal en los insertados en esta nueva forma de relación laboral. Algunos dicen que no es suficiente la ganancia del negocio, unos demuestran ser más capaces que otros. De forma neta se va creciendo en el número de licencias. $Y$ desde el punto de vista sindical es un reto para estos trabajadores y quienes le dirigen su afiliación. Lo antes señalado ha causado motivos para la devolución de licencias, por los elevados tributos a pagar y las dificultades para adquirir las materias primas, ante la inexistencia de un mercado mayorista con facilidades como ya antes citáramos.

\section{Actividades aprobadas como Trabajo por cuenta propia de mayor impacto}

El arrendamiento de viviendas tiene ya más de 20 años en Cuba, desde 1997 con el Decreto No. 171. Algo positivo que debo subrayar a partir de los Lineamientos y de la publicación en el año 2010 de las nuevas regulaciones para el Trabajo por Cuenta Propia, es que se eliminó el exceso de controles para arrendar una vivienda. De los 17 documentos que se exigían antes, en estos momentos solo quedan tres que son: la propiedad de la casa, el sello y un escrito de solicitud. ${ }^{22}$

Otras de las actividades que ha tenido un gran impacto ha sido la del transporte; no cabe dudas de que el trabajo por cuenta propia ha sido una alternativa en los difíciles años de período especial. A partir de las medidas aprobadas para flexibilizar el cuentapropismo, el Ministerio de Transporte ha tenido que ampliar su infraestructura con las Unidades Estatales de Tráfico para dar respuesta a las nuevas solicitudes en todos los municipios del territorio nacional. ${ }^{23}$

Papel que deben jugar los créditos bancarios en el fomento del Trabajo por Cuenta Propia por parte de la Administración Pública, en particular la Banca Central de Cuba

El crédito que tiene que ir a los cuentapropistas empieza a crecer en los años 90 del pasado siglo, debido a que este tipo de actividades quedaba al margen de la lógica del sistema financiero porque quienes las ejercen son personas sin un convincente respaldo económico. También el seguimiento de estos créditos es

\footnotetext{
${ }^{22}$ Consultar la página web del Ministerio de Justicia. www.gacetaoficial.cu, La Habana. Cuba.

${ }^{23}$ Ibídem no. 21
} 
difícil, porque las actividades son muchas y con una tasa de mortalidad de quiebra, muy alta.

En cuanto a esto debemos apuntar que en América Latina se ha empleado la vertiente de un mercado de créditos informal, dado por el préstamo de un familiar, un amigo o un usurero. Por lo tanto, una de las consecuencias de la ausencia de participación del mercado formal de créditos en el sector cuentapropista es el desarrollo de un mercado alternativo de las finanzas. Eso está sucediendo y va a continuar en el mundo, muchos especialistas plantean que se puede paliar desarrollando un tipo de banca especializada. En Cuba la lógica del sistema financiero del país siempre ha estado ubicada en la gran empresa estatal, de ahí que se requiere una recapacitación hacia esa nueva lógica, como existía antes de iniciarse el proyecto revolucionario, como era el caso del BANFAIC, aunque se han estado ya viabilizando créditos por parte de la banca cubana. ${ }^{24}$

\section{Una mirada al proceso de sindicalización de trabajadores por cuenta propia en el proyecto social cubano}

La Central de Trabajadores de Cuba (CTC) tiene tres fuentes fundamentales de afiliación: los trabajadores estatales, los no estatales y los jubilados, que bajo el principio de voluntariedad quieran sindicalizarse. Ahora, en los trabajadores no estatales vemos un nuevo potencial para la sindicalización. De los más de 328 mil trabajadores por cuenta propia existentes, cerca de 57 mil tiene vínculo laboral, por tanto, integran las filas de la CTC desde su actividad estatal. Investigaciones realizadas revelan que se han entrevistado a unos 270 mil cuentapropistas que no poseían esa condición y de ellos ya están afiliados más de 190 mil. Es un reto la afiliación de los cuentapropistas. Es un trabajo político de mucho interés incluso para la vida estatal.

Los principios para la sindicalización de los cuentapropistas son la voluntariedad y tratar de afiliarlos por sectores. De los 18 sindicatos que hoy existen en el país, 16 incluyen trabajadores por cuenta propia. En cuanto al tema, considero que se debe tener en cuenta por la Central de Trabajadores de Cuba que esta juega un papel muy importante de acuerdo con los principios socialistas, no crece igual el productor individual que el productor asalariado; el productor que contrata, que el productor contratado. No son los mismos intereses, no los puedo sindicalizar igual. Una de las cuestiones de más importante sobre el Trabajo por Cuenta Propia en la actualidad no son los obstáculos que tiene el mismo, que es una de las tantas cosas a ver en el reordenamiento, en la necesaria evolución que requiere el sistema social nuestro. También la propiedad estatal tiene muchísimos obstáculos. Hay que ver las cosas en su conjunto, y el trabajo por cuenta propia es sólo un asunto más a prestarle atención.

${ }^{24}$ Consultar materiales históricos sobre el desarrollo del sistema bancario en el país 
Se están cambiando reglas del juego, pero habrá que hacerlo de manera que no solo den eficiencia económica, sino que por encima de todo que fortalezcan nuestro proyecto social. En eso no se puede perder el rumbo. Con ello también debe ir acompañado de una cultura tributaria, del entendimiento de la necesidad de pagar esos impuestos y contribuciones para que se reviertan en bien de la sociedad. Todavía resulta insuficiente la asistencia que se le ha dado al contribuyente, la divulgación y el conocimiento alcanzado.

\section{2.- Requisitos para ejercer el trabajo por cuenta propia, causas de su extinción. Regulación jurídica actual}

La Resolución No. 33 de 6 de septiembre de 2011, del Ministerio de Trabajo y Seguridad Social, establece el Reglamento para ejercer el Trabajo por cuenta propia, en su artículo 4 del Capìtulo1 de las Generalidades: Pueden ejercer el trabajo por cuenta propia en las actividades aprobadas en este Reglamento, los residentes permanentes, mayores de 17 años que cumplan los requisitos establecidos, con los excepciones reguladas en la ley. La autorización para su ejercicio es personal e intransferible; establece los requisitos personales para desarrollar el mismo....

Del texto de este artículo se extrae la edad mínima exigible para ser autorizado el ejercicio del trabajo por cuenta propia: 17 años cumplidos, concordante con la edad laboral regulada en el artículo 26 del Código de Trabajo, aunque no con la plena capacidad para realizar actos jurídicos y ejercer los derechos que exige el artículo 29.1 del Código Civil cubano: 18 años

No se hace referencia alguna, explícitamente a la capacidad civil exigible, la cual nace restringida para realizar actos civiles si el sujeto no tiene 18 años cumplidos, se tendrá que presumir cuando hace alusión a los requisitos regulados en ley, de modo que, en ese supuesto, deberá cumplirse con lo preceptuado en el artículo 32 del Código Civil sobre la forma en que se suple la incapacidad de las personas, dada la imposibilidad en este caso de que la persona física actúe por sí mismo en la esfera mercantil, por lo que será necesario, cumplir con lo establecido en el Código de Familia ${ }^{25}$ y la legislación procesal civil; ser representado por padres con patria potestad o tutores nombrados o por el fiscal. Tampoco consta exigencia alguna sobre la libre disposición de los bienes. Al establecer 17 años como edad limite para el ejercicio de la labor se contradice a lo regulado en el Código de Comercio, en su artículo 4 apartado 1, tendrán capacidad legal para el ejercicio habitual del comercio las personas que reúnan las condiciones siguientes: haber cumplido la edad de veintiún años, ," y para los menores de veintiún año y los incapacitados se regula la posibilidad de poder continuar, por medio de sus guardadores, el comercio que hubieren ejercido sus padres o causantes. Este cuerpo normativo, a diferencia de la ya derogada Resolución No. 9 de 2005, 
antiguo Reglamento de la actividad, no hace alusión a si pueden llevar a cabo la labor los extranjeros con residencia permanente en el país, lo que no permite poner en correspondencia con lo establecido en el Código Civil vigente, cuando equipara los derechos de los ciudadanos cubanos al de los extranjeros residentes de forma permanente en el territorio nacional, para ejercer el trabajo por cuenta propia, sobre la base del cumplimiento de los requisitos establecidos y siempre que procedan de las fuentes enunciadas, es decir, de una procedencia lícita.

Del propio articulado se desprende otro requisito, el de realizar las actividades aprobadas, personalmente y, la prohibición de no poder transferir la autorización a una persona determinada, aun en aquellos casos donde el sujeto se encuentre imposibilitado; para ello establece el derecho que le asiste al trabajador (artículo 14), de solicitar una suspensión temporal del ejercicio al Director de Trabajo Municipal, incluyendo a la mujer cuentapropista, a la cual le asiste el derecho a una licencia de maternidad.

El Reglamento para el ejercicio del Trabajo por cuenta propia regula en su artículo 10, del Capítulo 2 referentes a los trabajadores registrados por las Direcciones de Trabajo, que los mismos pueden ejercer la actividad una vez recibida la autorización y realizada la afiliación al régimen de la seguridad social cuando corresponda, y la inscripción en el Registro de Contribuyentes en la Oficina de la ONAT de su municipio según corresponda, son estos otros requisitos a cumplir por todos aquellos con aspiraciones a desempeñara como un empresario mercantil individual en nuestro país aunque, la Resolución no lo exponga explícitamente. Incluso, se hace extensivo para los trabajadores cuyos servicios son contratados por titulares con autorización para ello, a partir de una solicitud escrita de parte del titular junto al que laboran (articulo12). Difieren de del requisito de inscripción en el Registro Mercantil previsto en el Código de Comercio (en su artículo 16 apartado primero).

Para los individuos que forman parte de los Ministerios de las Fuerzas Armadas y del Interior que deseen practicar las actividades del cuentapropismo deben someterse a las disposiciones requeridas por ambos como requisito indispensable para acceder a la autorización de la labor.

Causas de extinción del Trabajo pro cuenta propia:

Quedan reguladas en el artículo 16 de la Resolución 33/2011 y, constituyen las siguientes:

- Violaciones o incumplimientos de la legislación vigente, a solicitud de los funcionarios que atienden el trabajo por cuenta propia en las Direcciones de Trabajo Municipales: por lo tanto estos trabajadores se deben obediencia estricta a la ley, la actividad y los medios a utilizar para la misma han de ser legales; así como el estricto cumplimiento de las formalidades para su ingreso, el cumplimiento de sus obligaciones, etcétera. 
- Incumplimiento de sus obligaciones, a solicitud de la ONAT: se deriva de unas de las principales, el pago de los correspondientes tributos, ya que ostentan la capacidad económica exigible a la hora de gravar a los mismos y, como se trató durante la evolución de la institución dichos agentes económicos surgieron, para constituir una vía de el Estado ingresa a través del pago correspondiente efectuado.

- $\quad$ Solicitud expresa del trabajador

- De oficio o por solicitud del familiar por fallecimiento

- $\quad$ Notificación del retiro de la autorización, a solicitud de los organismos de inspección en el caso de violación de la legislación.

- $\quad$ Incumplimiento del pago de los créditos, a solicitud del banco.

- Vencimiento del término de la suspensión temporal, sin que se produzca la reincorporación a la actividad.

\section{Regulación Jurídica actual del trabajo por cuenta propia en Cuba}

Actualmente el texto legal regulador del trabajo por cuenta propia en nuestro país es la Resolución No.33 de 2011, de la Ministra de Trabajo y Seguridad Social, "Reglamento del ejercicio del trabajo por cuenta propia", sustituta de la Resolución No.32 de 2010 como motivos de las reformas realizadas en el país, en menos de un año, con el objetivo de ampliar su ejercicio. Así se amplia las actividades para desarrollar el mismo, de 178 a 181; se establece la posibilidad de la utilización de fuerza de trabajo contratada para todas las actividades permitidas; aumentan de 20 a 50 las capacidades deque pueden disponer los elaboradores-vendedores de alimentos y bebidas mediante servicio gastronòmico; también se exonera del pago del impuesto por la utilización de la fuerza de trabajo a los que contrataban hasta 5 trabajadores, introduce cambios al régimen de tributación; se reduce a una vez en el año la inspección técnica de los vehículos de los transportistas, se fijan las tarifas para los servicios técnicos de planificación física; y se determina el procedimiento y los plazos para el otorgamiento de la licencia sanitaria por parte del Ministerio de salud Pública.

Establece como deberes a cumplir por los trabajadores por cuenta propia, que pueden conllevar a las causales de la baja por los Directores de Trabajo del municipio de residencia; los siguientes:

- Cumplir la legislación vigente y las disposiciones de los organismos y órganos facultados;

- Cumplir con las obligaciones tributarias establecidas;

- Realizar exclusivamente la actividad o las actividades para las cuales están autorizadas y comercializar las producciones y servicios que realicen;

- $\quad$ Ejercer la actividad junto con los trabajadores contratados, excepto en las actividades de transporte;

- Utilizar en el ejercicio del trabajo, materias primas, materiales, equipos de procedencia lícita; 
- Responsabilizarse con la calidad de la producción que realizan y los servicios que realizan y los servicios que prestan;

- $\quad$ Mantener, en los lugares donde ejerzan la actividad, el cumplimiento de las normas sobre el ornato público, la seguridad en el trabajo, la higiene comunal, sanitaria y la preservación del medio ambiente;

- Mostrar a la autoridad competente la autorización que los acredite para ejercer la actividad, su inscripción en el registro de contribuyentes, así como cualquier otro documento que se establezca por los órganos del Estado y el Gobierno, organismos de la Administración Central del Estado y entidades nacionales, siempre que se encuentren en la elaboración, prestación del servicio, comercialización de las producciones o realicen gestiones de suministro u otras asociadas al ejercicio del trabajo por cuenta propia;

- Facilitar, durante el desarrollo de su trabajo, que se realicen las verificaciones y los controles que se requieran; y

- Recibir la asesoría de las autoridades competentes, solicitar y obtener la información que requieran sobre el ejercicio del trabajo por cuenta propia.

Para culminar el análisis del "Reglamento para el ejercicio del trabajo por cuenta propia", se hace referencia al contenido de las Disposiciones especiales y finales:

- La Disposición Especial Primera: Los Presidentes de los Consejos de la Administración provinciales, a propuesta u oído el parecer de los Consejos de la Administración municipales, ambos del Poder Popular, están facultados para limitar el otorgamiento de autorizaciones en determinada actividad.

- La Disposición Transitoria Única: ratifica la continuidad en el ejercicio de las actividades por cuenta propia de los profesionales universitarios o técnicos que se graduaron antes de 1964, y han venido desarrollando la misma de manera ininterrumpida, y se encuentren debidamente inscriptos en el Registro de Contribuyentes, no especifica si son las mismas actividades concedidas inicialmente a estos sujetos.

- La Disposición Final Primera: Los Ministerios de las Fuerzas Armadas Revolucionarias y del Interior, así como las máximas autoridades de dirección de las organizaciones políticas, sociales, y de masas, de acuerdo con sus particularidades, dictan las disposiciones que se requieran para la aplicación del presente Reglamento con respecto a los trabajadores de sus respectivos sistemas y las informan al Ministerio de Trabajo y Seguridad Social.

\section{La Ley no 73/94, del Sistema Tributario en Cuba ${ }^{26}$, su aplicación en el ejercicio del trabajo por cuenta propia}

Esta Ley fue aprobada el 4 de agosto de 1994 y se encuentra en vigor desde el 5 de agosto del propio año. Es el principal cuerpo preceptivo legal de la materia jurídico- tributaria que establece una serie de gravámenes concretos y contiene los conceptos, principios y regulaciones fundamentales en dicha materia. Sus sujetos pasivos van desde el simple ciudadano individual hasta las empresas y demás entidades. En el artículo 11 de la Ley se definen conceptos a los efectos de 
la materia tributaria y, en el caso de personas naturales, comprende a la persona física con capacidad para ser sujeto de derechos y obligaciones tributarias, y como persona jurídica a las empresas estatales, cooperativas, organizaciones sociales, políticas y de masas, sociedades civiles y mercantiles, asociaciones y organizaciones. En el Capítulo II, referido al Impuesto sobre ingresos personales, se hace referencia al trabajador por cuenta propia al disponer el artículo 18 que, a los efectos de la ley, la base imponible se constituye por los siguientes ingresos:

a) rendimiento de actividades mercantiles: los ingresos que se obtengan con el trabajo personal y el de su familia o personal asalariado en los casos que proceda.

Incluye las actividades del trabajo por cuenta propia y del desarrollo de actividades intelectuales, artísticas y manuales o físicas en general, ya sean de creación, reproducción, interpretación, aplicación de conocimientos y habilidades. En virtud de la obligación tributaria, que emerge del artículo anterior, los trabajadores por cuenta propia para poder hacer su contribución al presupuesto del Estado en forma real y concreta, tienen la necesidad de evidenciar, a todas aquellas personas encargadas de supervisarlos y controlarlos, que los ingresos declarados son ciertos, y que los productos utilizados tienen una procedencia legal. Con tales propósitos, es que se regula la obligación de conservar, portar y mostrar a las autoridades competentes la documentación relacionada con la actividad que desempeña, incluyendo la inscripción en el Registro de Contribuyentes, así como las facturas y vales de la adquisición de materias primas, materiales, equipos y herramientas.

La declaración jurada resulta un elemento esencial del sistema, pues constituye el documento a partir del cual la administración tributaria conoce el monto de la deuda fiscal del contribuyente, quién responderá por la veracidad de los datos que consigne en esa declaración, de ahí la trascendencia que la ley le atribuye al hecho de que aquel que presente la declaración incompleta, con inexactitudes o falsedades, podrá ser sancionado conforme a derecho.

Las sanciones pueden ser penales o administrativas, de acuerdo con la tipificación de cada conducta en uno u otro orden. El vigente Código Penal, que entró en vigor el 30 de abril de $1988^{27}$, tal y como fue modificado por el Decreto-ley No. 150 de 1994 y por el Decreto-ley No. 175 de 1997, incluye en los artículos 343 al 345 los delitos de Evasión Fiscal con varias modalidades, según las cuales pueden ser sancionadas las personas naturales que, en calidad de contribuyentes 0 responsables, incurran en algunas o varias de las conductas tipificadas en dichos artículos, con privación de libertad entre uno y ocho años, multas de hasta cinco mil cuotas, o ambos tipos de sanción en correspondencia con los hechos de que se trate, su entidad, características del autor y demás circunstancias. 


\section{El Derecho administrativo sancionador aplicado al ejercicio del Trabajo por Cuenta propia en Cuba}

Este Decreto-Ley tiene como antecedente legislativo, el Decreto No. 186 de 1994 "Sobre las contravenciones personales del trabajo por cuenta propia", cuya experiencia de aplicación, unida a la promulgación de la resolución Conjunta No 1 del MTSS y MFP de 1996, que aconsejan incluir nuevas contravenciones y modificar algunas de las existentes y el propio Decreto-Ley 174/97.La nueva normativa modificó los artículos 4, 6, 8 y 9 del vigente anteriormente.

De tal manera se pude definir como contravenciones, las infracciones de las normas y disposiciones relativo al ejercicio del trabajo por cuenta propia y su legislación complementaria, que carecen de peligrosidad social por la escasa entidad de sus resultados, pero deja establecido en su artículo 2 que si la infracción cometida se realiza utilizando materiales o medios de procedencia ilícita, o por su significación económica, peligrosidad social, las circunstancias concurrentes y antecedentes personales del inculpado se tipificaran algunos de los delitos contemplados como actividades económicas ilícitas u otros, la autoridad facultada debe abstenerse de proceder por la vía administrativa, y denunciará los hechos como un posible delito.

El Decreto-ley 174 de 1997 va recorriendo las contravenciones y sus sanciones, partiendo de las exigencias propias del ejercicio de la actividad; el incumplimiento de obligaciones como el no ingreso de la deuda tributaria; etc. Define cuáles son las autoridades facultadas para imponer las multas y demás medidas y resolver los recursos; estipula la forma en que se pagarán las multas y el procedimiento a seguir para cumplimiento de las demás medidas como el embargo de sueldo, salario, pensión u otros ingresos periódicos que perciba el obligado, las cuentas bancarias o muebles. Los trabajadores por cuenta propia, en cuanto personas naturales, son sujetos pasivos de otros impuestos y tasas, vinculados o no con su labor, como el impuesto sobre el transporte terrestre, sobre la transmisión de bienes y herencias, la tasa por radiación de anuncios y propaganda comercial, etc.

El cambio introducido por el Decreto-Ley 274 del 2010 radica en:

Se establecen tres contravenciones específicamente: ejercer una actividad que no esté legalmente autorizada, por la cual se regula la imposición de una multa cuya cuantía menor es de quinientos pesos (500.00) y puede llegar hasta mil quinientos (1500.00); imponiéndose la cuantía máxima, en todos aquellos casos de sea una persona que no presente la documentación personal (articulo 1 del Decreto-Ley 274/2011). Otras de las contravenciones es en la situación de ejercer una actividad de las legalmente establecidas y no se presente la documentación que lo acredite como trabajador por cuenta propia, a la cual le corresponde como sanción una multa que va desde cuatrocientos pesos (400.00) hasta mil doscientos (1200.00); tiene como agravante la no presencia de los documentos de identidad personal del sujeto, acudiéndose a imponer la cuantía mayor y, por ultimo, el caso de ejercer una actividad para la cual esta legalmente autorizado, pero incurre en 
un grupo de violaciones, entre las que se destacan: utilizar más de las plazas autorizadas en la legislación en la venta de alimentos y bebidas mediante servicio gastronómico, comercializar, total o parcialmente, en moneda extranjera o en pesos convertibles, sin haberlo declarado, no mostrar, a solicitud de la autoridad facultada, evidencias de la ilicitud de los productos, entre otras,( artículos 2 y 3,respectivamente, del referido Decreto-Ley).

Se regulan también las contravenciones del trabajo por cuenta propia en materia sanitaria, definiendo por además, la reincidencia en materia de contravenciones del desarrollo de dicha labor, entendiendo como tal a la persona que incurrió en una misma contravención dentro del propio año del año inmediato anterior (artículo 9). Su Disposición Transitoria otorga el derecho a las personas que al momento de entrar en vigor el texto legal tuvieran suspendida la autorización para el ejercicio del trabajo por cuenta propia por las contravenciones que por este se modifiquen a inscribirse como trabajadores por cuenta propia sin atenerse al término de suspensión originalmente impuesto.

\section{El Régimen especial de Seguridad Social para los trabajadores por cuenta propia“"}

El Decreto-Ley No. 278 del 2010 dispone que se establece un régimen especial de Seguridad Social dirigido a la protección de los trabajadores por cuenta propia que no son sujetos del régimen general de la seguridad social o cualquier otro régimen especial y, la afiliación al régimen especial de Seguridad Social de estos trabajadores es obligatoria y constituye un requisito indispensable para que ejerzan su trabajo y reciban beneficios de la Seguridad Social. El mismo ofrece protección al cuentapropista ante la vejez, la invalidez parcial o permanente y, en caso de muerte a su familia, así como a la trabajadora en ocasión de la maternidad (artículos 1, 2 y 3 del Decreto- Ley No. 278). El Decreto-Ley No. 284 realiza una modificación al mismo en cuanto dispone: Se le adiciona una Disposición Especial al Decreto-Ley No. 278, que será la cuarta: Están exonerados de la obligación de afiliarse al régimen de Seguridad Social, la trabajadora de 60 años o más y el trabajador de 65 años o más de edad. Los trabajadores que tengan cumplidas esas edades $y$, de forma voluntaria permanezcan afiliados al régimen especial o lo hagan con posterioridad a la vigencia del presente Decreto-Ley, recibirán los beneficios que les corresponden. Modifica las Disposiciones Primera y Segunda del referido texto legal,

Primera: Durante el término de diez años, contados a partir del mes siguiente al de la fecha de entrada en vigor del presente Decreto-Ley, el trabajador que ingrese al régimen con menos de 50 años de edad, si es mujer y 55 años de edad, si es hombre, puede abonar de forma voluntaria a la Seguridad Social, con efecto retroactivo, la contribución correspondiente por el tiempo que considere oportuno, a partir de la fecha en que debidamente autorizado ejerce la actividad. 
Segunda: Durante el término de diez años, contados a partir del mes siguiente al de la fecha de entrada en vigor del presente Decreto-Ley, el trabajador que ingrese al régimen con menos de 50 años de edad, si es mujer y 55 años de edad, si es hombre, puede abonar de forma voluntaria a la Seguridad Social, con efecto retroactivo, la contribución referida en los artículos 12 y 13, por el tiempo que considere oportuno, a partir de la fecha en que debidamente autorizado ejerza la actividad. Estas regulaciones jurídicas complementan el conjunto de disposiciones que de manera específica atañen al trabajador por cuenta propia visto como sujeto determinado de derecho, aunque como persona natural le son aplicables el resto de las normativas vigentes en el país, debiendo ajustarse en lo que a reclamaciones económicas se refiere al procedimiento civil o económico en dependencia de la jurisdicción que le corresponda.

\section{CONCLUSIONES}

Primera: En el Código de Comercio español y en el vigente en Cuba se le reconoce personalidad jurídica al empresario individual mercantil (o comerciante), siempre que cumpla con los requisitos legalmente establecidos de capacidad legal, ejercicio habitual del comercio, ejercicio del comercio en nombre propio y que la actividad a desarrollar esté autorizada por la ley.

Segunda: Del análisis de los principios en que se informa la legislación que rige en Cuba para los trabajadores por cuenta propia se aprecia una ruptura conceptual elemental en cuanto a la actividad que pueden desarrollar estos y la que realizan los empresarios individuales, toda vez que la primera se desarrolla solo como complemento de la actividad estatal, siendo renovable la autorización para su ejercicio, con carácter municipal y solo les está permitido actuar de forma personal, mientras que el empresario individual actúa por su propia cuenta y también por cuenta de terceros, pudiendo actuar por medio de representantes, con el límite que pueda establecer la ley para actividades mercantiles, sin limitaciones territoriales.

Tercera: Que el trabajo por cuenta propia es un asunto más a prestarle atención pues estamos cambiando reglas del juego dentro de nuestro proyecto social, pero tenemos que hacerlo de manera que no solo den eficiencia económica, sino que por encima de todo que fortalezcan nuestro sistema económico.

\section{BIBLIOGRAFÍA}

BARRERA GRAF, Jorge. El Derecho Mercantil en la América Latina. Editora Universidad Nacional Autónoma de México. 1963.

BROSETA PONT, Manuel: Manual de Derecho Mercantil, Editorial Tecnos S.A, Madrid, España, 1991. 
COLECTIVO DE AUTORES, Nociones de Derecho Mercantil, Editorial Félix Valera, 2004, pag.17.

COLECTIVO DE AUTORES: Nociones de Derecho Mercantil (para estudiantes de contabilidad), 1ª ed., Ed. Félix Varela, La Habana, 2004.

URÍA, RODRÍGO: Curso de Derecho Mercantil, Editorial Marcial Pons, Madrid España.

GARRIGUES, Joaquín: Curso de Derecho Mercantil, Tomo I, 8va Edición, Madrid, España, 1983.

RODRÍGUEZ RODRÍGUEZ, Joaquín: Curso de Derecho Mercantil, Tomo I, Vigésima primera edición, Editorial Porrúa, S.A, México, D.F, 1994.

JIMÉNEZ SÁNCHEZ, Guillermo (Coordinador): Derecho Mercantil, Tomo II, 2da ed., corregida, Editorial Ariel, Barcelona, España, 1992.

RODRIGO URÍA Y MENÉNDEZ AURELIO (Coordinadores): Curso de Derecho Mercantil, Tomo I, Editorial Civitas S.L, Reimpresión, Madrid, España, 2001.

RUIZ DE VELASCO, Adolfo: Manual de Derecho Mercantil, Editores Deusto S.A., Bilbao, España, 1992

SÁNCHEZ CALERO, Fernando: Instituciones de Derecho Mercantil, Tomo I, 19na edición, Madrid, España, Editorial Revista de Derecho Privado, 1996.

VICENT CHULIÁ, Francisco: Compendio Crítico de Derecho Mercantil, Tomo II, 3era edición, Parte I, Editorial José María Bosch, España, 1991.

RODRÍGUEZ García, J. (1995): "Cuba 1990-1995: reflexiones sobre una política económica acertada". Cuba Socialista, La Habana, p. 25.

PALLARES, Eduardo. Derecho Comercial Mexicano. 1922. México.

NISEN, Ricardo. Estructura económica societaria. Universidad Nacional La Plata.

VILA NOYA, MSc. Lisette: El trabajo por cuenta propia en Cuba Trabajo de Ejercicio Académico que le sirvió para homologar en Cuba el título de Master en Derecho Mercantil y Financiero de la Universidad de Barcelona.

VIVANTE, César. Derecho mercantil. Tribunal Superior de Justicia Federal. Universidad de Bolonia. Italia. Editora Madrid.2003. 


\section{Legislación}

Constitución de la República de Cuba. Publicada en la Gaceta Oficial, 8 de julio de 1940, Ed. Minerva, La Habana.

Constitución de la República de Cuba. Reformas aprobadas por la Asamblea Nacional del Poder Popular. Granma, Ciudad de La Habana, edición especial, jun, 1992.

Ley No. 1289 de 14 de febrero de 1975, Código de Familia (2004): La Habana: Ley No 7 de 19 de agosto de 1977, Ley de Procedimiento Civil, Administrativo y Laboral (2004):

Ley No. 49 de 28 de diciembre de 1984, Código de Trabajo.

Ley No 59 de 16 de julio de 1987, Código Civil (1989): Ed. Ciencias Sociales, Ciudad de La Habana.

Ley No. 62 de 30 de abril de 1988, Código Penal (2004).

Ley No. 73 de 4 de agosto de1994, Ley del Sistema Tributario (s. f.): Ed. Sangova, Madrid, col. Textos Legales.

Ley No. 77 de 5 de septiembre de 1995, Ley de la Inversión Extranjera, Ed. Sangova, Madrid, col. Textos Legales.

Decreto-ley No. 141 de 8 de septiembre de 1993del Consejo de Estado, Sobre el ejercicio del trabajo por cuenta propia.

Decreto-ley No. 174 de 9 de mayo de 1997 del Consejo de Estado, De las contravenciones personales de las regulaciones del trabajo por cuenta propia. Publicado en la Gaceta Oficial de la República, edición ordinaria, de 30 de junio.

Decreto-ley No. 241 de 26 de septiembre de 2006 modificativo de la Ley de Procedimiento Civil, Administrativo y Laboral.

Resolución Conjunta No. 1 de 18 de abril de 1996, "Reglamento del ejercicio del trabajo por cuenta propia" del Ministerio de Trabajo y Seguridad Social y Ministerio de Finanzas y Precios.

Resolución No. 11 de 25 de marzo de 2004 del Ministerio de Trabajo y Seguridad Social, Reglamento sobre el ejercicio del trabajo por cuenta propia.

Resolución No. 9 de 11 de marzo de 2005 del Ministerio de Trabajo y Seguridad Social. Reglamento sobre el ejercicio del trabajo por cuenta propia.

Compendio de Regulaciones del Ejercicio del Trabajo por Cuenta Propia y los procesos de reducción de plantillas infladas, Empresa Poligráfica, Holguín, 2011.

Instrucción No. 27 de 15 de junio de 2006 del Viceministro de Trabajo y Seguridad Social, "Procedimiento para otorgar la Licencia para ejercer el Trabajo por Cuenta Propia". 